\title{
Polymer-Bound Oxathiaphospholane: A Solid-Phase Reagent for Regioselective Monothiophosphorylation and Monophosphorylation of Unprotected Nucleosides and Carbohydrates
}

Yousef Ahmadibeni ${ }^{\mathrm{a}}$ and Keykavous Parang ${ }^{\mathrm{a}, *}$

${ }^{a}$ Department of Biomedical and Pharmaceutical Sciences, College of Pharmacy, The University of Rhode Island, Kingston, Rhode Island, 02881.

\section{Table of Contents:}

1. General.

2. Solid-phase monophosphorylation using NovaSyn ${ }^{\mathrm{TM}}$ Tentagel resin bound-1,3,2oxathiaphospholane (3).

3. Solid-phase monothiophosphorylation using NovaSyn ${ }^{\mathrm{TM}}$ Tentagel resin bound 1,3,2oxathiaphospholane (3).

4. Solid-phase monophosphorylation using acetamidomethyl $\mathrm{NovaGel}^{\mathrm{TM}}$ resin bound-1,3,2oxathiaphospholane (6).

5. Solid-phase monothiophosphorylation using NovaGel $^{\mathrm{TM}}$ resin-bound 1,3,2oxathiaphospholane (6).

6. References for physical and spectral properties. 


\section{Supporting Information}

\section{Experimental}

1. General: All reactions were carried out in Bio-Rad polypropylene columns by shaking and mixing using Glass-Col small tube rotator in dry conditions at room temperature unless otherwise stated. Real-time monitoring of loading of compounds on resin beads was carried out with a Thermo-Nicolet 550 FT-IR spectrophotometer coupled with a Nic-Plan microscope using OMNIC software. The chemical structures of final products were confirmed by nuclear magnetic resonance spectra $\left({ }^{1} \mathrm{H} \mathrm{NMR},{ }^{13} \mathrm{C} \mathrm{NMR},{ }^{31} \mathrm{P} \mathrm{NMR}\right)$ determined on a Bruker NMR spectrometer (400 MHz). ${ }^{13} \mathrm{C}$ NMR spectra were acquired using $J$ modulated spin echo technique where methyl and methane carbon resonances appear as positive peaks, and methylene and quaternary carbon resonances appear as negative peaks. Chemical shifts are reported in parts per millions (ppm). The chemical structures of compounds were confirmed by a high-resolution PE Biosystems Mariner API-time of flight mass spectrometer. The substitution of the resins for each step was estimated from the weight gain of the resin. Total isolated yields for final products were calculated based on the loading of NovaSyn ${ }^{\mathrm{TM}}$ Tentagel bromo resin $(\mathbf{1}, 0.35 \mathrm{mmol} / \mathrm{g})$ and bromoacetamidomethyl NovaGel ${ }^{\mathrm{TM}} \operatorname{resin}(4,0.64 \mathrm{mmol} / \mathrm{g})$ and the amount of monophosphorylated and monothiophosphorylated products. 
2. Solid-phase monophosphorylation using NovaSyn ${ }^{\mathrm{TM}}$ Tentagel resin bound-1,3,2oxathiaphospholane (3).

\section{Preparation of NovaSyn ${ }^{\mathrm{TM}}$ Tentagel resin-bound 2,3-dimercapto-1-propanol (2).}

NovaSyn $^{\mathrm{TM}}$ Tentagel bromo resin $(1,5.0 \mathrm{~g}, 130 \mu \mathrm{m}$ beads, $0.35 \mathrm{mmol} / \mathrm{g})$ was swelled in dry NMP (35 mL) and was shaken at room temperature for $15 \mathrm{~min}$. 2,3-Dimercapto-1-propanol (702 $\mu \mathrm{L}, 7.0 \mathrm{mmol})$ and potassium carbonate $(0.97 \mathrm{~g}, 7.0 \mathrm{mmol})$ were added to the swelled resin. The shaking was continued for $24 \mathrm{~h}$ at room temperature. The resin was filtered and washed with dry NMP $(2 \times 35 \mathrm{~mL})$, dry DCM $(2 \times 35 \mathrm{~mL})$, dry MeOH $(3 \times 35 \mathrm{~mL})$, and dried under vacuum to give 2 (5.074 g, 98\%, $0.34 \mathrm{mmol} / \mathrm{g})$. IR $\left(\mathrm{cm}^{-1}\right): 3495(\mathrm{OH})$.

Preparation of NovaSyn ${ }^{\mathrm{TM}}$ Tentagel resin-bound 2-(N,N-diisopropylamine)-1,3,2oxathiaphospholane (3). $N, N$-Diisopropyl phosphoramidite dichloride ( $984 \mu \mathrm{L}, 7.0 \mathrm{mmol}$ ) and pyridine $(566 \mu \mathrm{L}, 7.0 \mathrm{mmol})$ were added to the swelled solution of $2(5.074 \mathrm{~g}, 0.34 \mathrm{mmol} / \mathrm{g})$ in anhydrous NMP $(35 \mathrm{~mL})$. The mixture was shaken for $24 \mathrm{~h}$ at room temperature. The resin was collected by filtration and washed with NMP $(2 \times 30 \mathrm{~mL}), \mathrm{DCM}(2 \times 30 \mathrm{~mL})$, and dry MeOH $(3$ $\times 30 \mathrm{~mL})$, respectively, and dried under vacuum to give $3(5.292 \mathrm{~g}, 97 \%, 0.32 \mathrm{mmol} / \mathrm{g}) . \mathrm{IR}\left(\mathrm{cm}^{-}\right.$ 1): 1037 (P-O-C). Polymer-bound 2-(N,N-diisopropylamine)-1,3,2-oxathiaphospholane (3) was stable at room temperature for $24 \mathrm{~h}$ drying period and was kept at $-20{ }^{\circ} \mathrm{C}$ for two weeks before using in the next reaction. 
Preparation of NovaSyn ${ }^{\mathrm{TM}}$ Tentagel resin-bound 5'-O-(1,3,2-

oxathiaphospholane)thymidine (7a), 5'-O-(1,3,2-oxathiaphospholane)uridine (7b), 5'-O-

(1,3,2-oxathiaphospholane)adenosine (7c), 6-O-(1,3,2-oxathiaphospholane)- $\alpha, \beta$-D-mannose

(7d), 6'-O-(1,3,2-oxathiaphospholane)-6-O- $\alpha$-D-galactopyranosyl- $\alpha, \beta-D-g l u c o s e ~(7 e)$.

Nucleosides and carbohydrates (a-e, $0.64 \mathrm{mmol})$ and 1- $H$-tetrazole $(34 \mathrm{mg}, 0.48 \mathrm{mmol})$ were added to $3(500 \mathrm{mg}, 0.32 \mathrm{mmol} / \mathrm{g})$ in anhydrous THF $(2 \mathrm{~mL})$ and DMSO $(2-3 \mathrm{~mL})$ or in anhydrous DMSO $(5 \mathrm{~mL})$ in case of adenosine. The mixture was shaken for $24 \mathrm{~h}$ at room temperature. The resin was collected by filtration and washed with DMSO $(3 \times 15 \mathrm{~mL})$, THF $(2$ $\times 10 \mathrm{~mL})$, and $\mathrm{MeOH}(3 \times 15 \mathrm{~mL})$, respectively, and dried under vacuum to give 7a-e (511-543 mg), respectively. IR (cm ${ }^{-1}$ ): 7a: $3514(\mathrm{OH}), 1037$ (P-O-C); 7b: 3515 (OH), 1033 (P-O-C); 7c: 3517 (OH), 1025 (P-O-C); 7d: 3518 (OH), 1034 (P-O-C); 7 e: 3419 (OH), 1034 (P-O-C).

Oxidation of NovaSyn ${ }^{\mathrm{TM}}$ Tentagel resin-bound phosphitylated precursors, $7 \mathrm{a}-\mathrm{e}$, to polymer-bound 1,3,2-oxathiaphospholane phosphotrieseter derivatives of thymidine (9a), uridine (9b), adenosine(9c), $\alpha, \beta$-D-mannose (9d), and 6- $O$ - $\alpha$-D-galactopyranosyl- $\alpha, \beta-D-$ glucose (9e). tert-Butyl hydroperoxide in decane (5-6 M, $128 \mu \mathrm{L}, 0.64 \mathrm{mmol})$ was added to the resins (7a-e, 511-543 mg) in THF ( $3 \mathrm{~mL})$. After $1 \mathrm{~h}$ shaking at room temperature, the resins were collected by filtration and washed with DMSO $(10 \mathrm{~mL})$, THF $(2 \times 10 \mathrm{~mL})$, and $\mathrm{MeOH}(3 \times 15$ $\mathrm{mL})$, respectively, and were dried under vacuum to give 9a-e (512-545 mg). IR $\left(\mathrm{cm}^{-1}\right)$ : 9a: 3417 (O-H), 1033 (P-O-C); 9b: 3409 (O-H), 1031 (P-O-C); 9c: 3405 (O-H), 1035 (P-O-C); 9d: 3420 (O-H), 1032 (P-O-C); 9e: 3415 (O-H), 1037 (P-O-C). Polymer-bound 1,3,2-oxathiaphospholane phosphotrieseter derivatives 9a-e were stable at room temperature for $24 \mathrm{~h}$ drying period and were used immediately after drying for the use in the next reaction. 
Preparation of thymidine-5'-O-monophosphate (11f), uridine-5'-O-monophosphate (11g), adenosine-5'-O-monophosphate (11h), $\alpha, \beta$-D-mannose-6- $O$-phosphate (11i), and 6-O- $\alpha$-Dgalactopyranosyl-6'-O-phosphate- $\boldsymbol{\alpha}, \boldsymbol{\beta}$-D-glucose (11j). To the swelled resins $(\mathbf{9 a - e , ~ 5 1 2 - 5 4 5}$ $\mathrm{mg})$ in anhydrous DCM (3 mL) was added DBU $(64 \mu \mathrm{L}, 0.64 \mathrm{mmol})$ and 3-hydroxypropionitrile $(0.64 \mathrm{mmol}, 46 \mu \mathrm{L})$. After $48 \mathrm{~h}$ shaking of the mixture at room temperature, the resins were collected by filtration and washed with DCM $(2 \times 10 \mathrm{~mL})$, THF $(2 \times 10 \mathrm{~mL})$, and $\mathrm{MeOH}(3 \times 10$ $\mathrm{mL})$, respectively. The solvents of filtrate solutions were immediately evaporated at room temperature for $11 \mathbf{f}$ and $\mathbf{1 1 g}$ and at $-20^{\circ} \mathrm{C}$ for $\mathbf{1 1 h}-\mathbf{j}$, respectively. The residues were mixed with Amberlite AG-50W-X8 (100-200 mesh, hydrogen form, $500 \mathrm{mg}, 1.7 \mathrm{meq} / \mathrm{g})$ in water:dioxane $(70: 30 \mathrm{v} / \mathrm{v}, 3 \mathrm{~mL})$ for $30 \mathrm{~min}$ at room temperature for $\mathbf{1 1 f}$ and $\mathbf{1 1 g}$ and at $-20{ }^{\circ} \mathrm{C}$ for $\mathbf{1 1 h}-\mathbf{j}$, respectively. After filtration, the solvents were evaporated and the crude products were purified using $\mathrm{C}_{18}$ Sep-Pak using appropriate solvents. The solvents were evaporated and the residues were dried under vacuum to yield 11f-j. The total isolated yields for $\mathbf{1 1 f - j}$ were: $\mathbf{1 1 f}(37.7 \mathrm{mg}$, 71\%), 11g (38.8 mg, 69\%), 11h (45.2 mg, 75\%), 11i (28.0, 62\%), 11j (41.8, 57\%). The compounds were characterized by ${ }^{1} \mathrm{H} \mathrm{NMR},{ }^{13} \mathrm{C} \mathrm{NMR},{ }^{31} \mathrm{P} \mathrm{NMR}$, and high resolution mass spectrometer (ESI-TOF). The chemical structures were confirmed with comparing their spectral properties with authentic samples purchased from Sigma-Aldrich and Acros Organics and literature. Compounds $\mathbf{1 1 \mathbf { i } ^ { 3 8 }}$ and $\mathbf{1 1} \mathbf{j}^{30}$ have been previously characterized by ${ }^{1} \mathrm{H} \mathrm{NMR}$ and ${ }^{13} \mathrm{C}$ NMR. Compounds 11f $,{ }^{39} \mathbf{1 1 g},{ }^{39}$ and $\mathbf{1 1} \mathbf{h}^{39-41}$ have been previously characterized by ${ }^{1} \mathrm{H}$ NMR. ${ }^{13} \mathrm{C}$ NMR (DMSO- $\left.d_{6}\right): \delta$ 11f: $12.64\left(5-\mathrm{CH}_{3}\right), 39.82\left(\mathrm{C}-2^{\prime}\right), 61.71\left(\mathrm{C}-5^{\prime}\right), 70.83\left(\mathrm{C}-3^{\prime}\right), 84.16,87.61$ (C-4', C-1'), 109.79 (C-5), $136.52(\mathrm{C}-6), 150.86(\mathrm{C}-2 \mathrm{C}=\mathrm{O}), 164.18(\mathrm{C}-4 \mathrm{C}=\mathrm{O}) ;{ }^{13} \mathrm{C}$ NMR $\left(\mathrm{D}_{2} \mathrm{O}\right)$

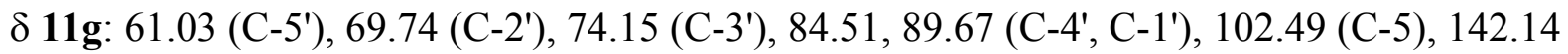


(C-6), $151.83(\mathrm{C}-2 C=\mathrm{O}), 166.34(\mathrm{C}-4 C=\mathrm{O}) ;{ }^{13} \mathrm{C}$ NMR (DMSO- $\left.d_{6}\right): \delta$ 11h: $65.98\left(\mathrm{C}-5^{\prime}\right) ; 71.31$

(C-2'), 74.45 (C-3'), 84.14, 87.99 (C-4', C-1'), 119.67 (C-5), 140.72 (C-8), 150.14 (C-4), 151.90

(C-2), 155.58 (C-6). ${ }^{31} \mathrm{P}$ NMR (in $\mathrm{D}_{2} \mathrm{O}$ and $\mathrm{H}_{3} \mathrm{PO}_{4} 85 \%$ in water as external standard): $\delta \mathbf{1 1 f}$ :

4.54 (s); 11g: 4.56 (s); 11i; 4.33 (s); 11j: 4.95 (s); ${ }^{31} \mathrm{P}$ NMR (in DMSO and $\mathrm{H}_{3} \mathrm{PO}_{4} 85 \%$ in water as external standard): $\delta$ 11h: $4.39(\mathrm{~s})$.

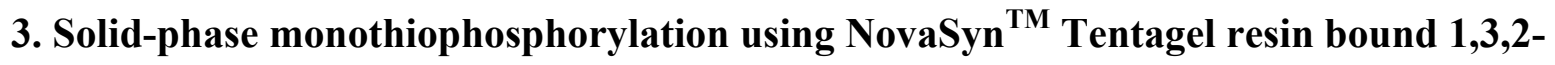
oxathiaphospholane (3).

Sulfurization of NovaSyn ${ }^{\mathrm{TM}}$ Tentagel resin-bound phosphitylated precursors, $7 \mathrm{a}-\mathrm{e}$, to NovaSyn $^{\text {TM }}$ Tentagel resin-bound 1,3,2-oxathiaphospholane thiophosphotrieseter derivatives of thymidine (12a), uridine (12b), adenosine (12c), $\alpha, \beta$-D-mannose (12d), and 6$\boldsymbol{O}$ - $\boldsymbol{\alpha}$-D-galactopyranosyl- $\alpha, \boldsymbol{\beta}$-D-glucose (12e). Beaucage's reagent ( $3 H$-1,2-benzodithiole-3one 1,1-dioxide) (128 mL, $0.64 \mathrm{mmol})$ was added to the resins (7a-e, 511-543 mg) in AcCN (4 $\mathrm{mL}$ ). After $6 \mathrm{~h}$ shaking at $40{ }^{\circ} \mathrm{C}$, the resins were collected by filtration and washed with AcCN (2 $\times 10 \mathrm{~mL})$, THF $(2 \times 10 \mathrm{~mL})$, and $\mathrm{MeOH}(3 \times 10 \mathrm{~mL})$, respectively, and were dried under vacuum to give 12a-e (515-547 mg). IR ( $\left.\mathrm{cm}^{-1}\right)$ : 12a: 3507 (O-H), 1029 (P-O-C); 12b: $3511(\mathrm{O}-\mathrm{H}), 1033$ (P-O-C); 12c: 3320 (O-H), 1026 (P-O-C); 12d: 3506 (O-H), 1029 (P-O-C); 12e: 3489 (O-H), 1035 (P-O-C). Polymer-bound 1,3,2-oxathiaphospholane thiophosphotrieseter derivatives 12a-e were stable at room temperature for $24 \mathrm{~h}$ drying period and were used immediately after drying for the use in the next reaction. 
Preparation of thymidine-5'- $O$-monothiophosphate (18k), uridine-5'- $O$-monothiophosphate (181), adenosine-5'- $O$-monothiophosphate (18m), $\alpha, \beta$-D-mannose-6- $O$-thiophosphate (18n), and 6- $O$ - $\alpha$-D-galactopyranosyl-6' $-O$-thiophosphate- $\alpha, \beta$-D-glucose (180). To the swelled resins (12a-e, 515-547 $\mathrm{mg})$ in anhydrous DMSO $(5 \mathrm{~mL})$ was added DBU (64 $\mu \mathrm{L}, 0.64 \mathrm{mmol})$ and 3-hydroxypropionitrile $(0.64 \mathrm{mmol}, 46 \mu \mathrm{L})$. After $48 \mathrm{~h}$ shaking of the mixture at room temperature, the resins were collected by filtration and washed with DCM (10 mL), THF (10 $\mathrm{mL})$, and $\mathrm{MeOH}(10 \mathrm{~mL})$, respectively. The solvents of filtrate solutions were immediately evaporated at room temperature for $\mathbf{1 8 k}$ and $18 \mathrm{l}$ and at $-20{ }^{\circ} \mathrm{C}$ for $\mathbf{1 8 m - 0}$, respectively. The residues were mixed with Amberlite AG-50W-X8 (100-200 mesh, hydrogen form, 500 mg, 1.7 meq/g) in water:dioxane $(70: 30 \mathrm{v} / \mathrm{v}, 3 \mathrm{~mL})$ for $30 \mathrm{~min}$ at room temperature for $\mathbf{1 8 k}$ and $\mathbf{1 8 1}$ and at $-20{ }^{\circ} \mathrm{C}$ for $\mathbf{1 8 m - 0}$, respectively. After filtration, the solvents were evaporated and the crude products were purified using $\mathrm{C}_{18}$ Sep-Pak using appropriate solvents. The solvents were evaporated and the residues were dried under vacuum to yield 18k-o. The total isolated yields for 18k-o were: 18k (37.0 mg, 63\%), $18 \mathbf{l}(38.9$ mg, 66\%), 18m (44.1 mg, 70\%), 18n (26.9 mg, 56\%), 180 (38.8 mg, 51\%). The compounds were characterized by ${ }^{1} \mathrm{H}$ NMR, ${ }^{13} \mathrm{C}$ NMR, ${ }^{31} \mathrm{P}$ NMR, and high resolution mass spectrometer (ESI-TOF).

Thymidine-5'-O-monothiophosphate (18k). ${ }^{1} \mathrm{H}$ NMR $\left(\mathrm{D}_{2} \mathrm{O}\right): \delta 1.87\left(\mathrm{~d}, J_{5-\mathrm{CH}_{3}, 6}=1.3 \mathrm{~Hz}, 5-\right.$ $\left.\mathrm{CH}_{3}, 3 \mathrm{H}\right) ; 2.25-2.40$ (m, H-2', H-2", $\left.2 \mathrm{H}\right), 3.65\left(\mathrm{dd}, J_{5^{\prime}, 5^{\prime \prime}}=12.5, J_{5^{\prime}, 4^{\prime}}=4.9 \mathrm{~Hz}, \mathrm{H}-5^{\prime}, 1 \mathrm{H}\right), 3.73(\mathrm{dd}$, $\left.J_{5^{\prime}, 5^{\prime \prime}}=12.5, J_{5^{\prime \prime}, 4^{\prime}}=3.8 \mathrm{~Hz}, \mathrm{H}-5^{\prime \prime}, 1 \mathrm{H}\right), 3.95-4.04\left(\mathrm{~m}, \mathrm{H}-4^{\prime}, 1 \mathrm{H}\right), 4.41-4.47$ (m, H-3',1H), $6.23(\mathrm{t}, J$ $\left.=6.7 \mathrm{~Hz}, \mathrm{H}-1^{\prime}, 1 \mathrm{H}\right), 7.70\left(\mathrm{~d}, J_{6,5-\mathrm{CH}_{3}}=1.3 \mathrm{~Hz}, \mathrm{H}-6,1 \mathrm{H}\right) ;{ }^{13} \mathrm{C} \mathrm{NMR}\left(\mathrm{D}_{2} \mathrm{O}\right): \delta 12.65\left(5-\mathrm{CH}_{3}\right), 39.82$ (C-2'), 61.71 (C-5'), 70.83 (C-3'), 84.16, 87.61 (C-4', C-1'), 109.79 (C-5), 136.52 (C-6), 150.86 
(C-2 $C=0$ ), $164.18(\mathrm{C}-4 C=\mathrm{O}) ;{ }^{31} \mathrm{P}$ NMR (in $\mathrm{D}_{2} \mathrm{O}$ and $\mathrm{H}_{3} \mathrm{PO}_{4} 85 \%$ in water as external standard): $\delta 43.35$ (s); HR-MS (ESI-TOF) (m/z) calcd. 338.2741, found $338.2669[\mathrm{M}]^{+}, 339.2737[\mathrm{M}+\mathrm{H}]^{+}$.

Uridine-5'-O-monothiophosphate (181). ${ }^{1} \mathrm{H}$ NMR $\left(\mathrm{D}_{2} \mathrm{O}\right): \delta 3.92\left(\mathrm{dd}, J_{5^{\prime}, 5^{\prime \prime}}=11.8, J_{5^{\prime}, 4^{\prime}}=6.0 \mathrm{~Hz}\right.$, H-5', $1 \mathrm{H}), 3.78\left(\mathrm{dd}, J_{5^{\prime}, 5^{\prime \prime}}=11.8, J_{5^{\prime \prime}, 4^{\prime}}=4.9 \mathrm{~Hz}, \mathrm{H}-5^{\prime \prime}, 1 \mathrm{H}\right), 4.20-4.24\left(\mathrm{~m}, \mathrm{H}-4^{\prime}, 1 \mathrm{H}\right), 4.29-4.34$ (m, H-3',1H), 4.37-4.40 (m, H-2', H-2", 2H), 5.93-5.98 (m, H-1', H-5, 2H), 8.09 (d, $J_{6,5}=8.1 \mathrm{~Hz}, \mathrm{H}-$ $6,1 \mathrm{H}) ;{ }^{13} \mathrm{C}$ NMR $\left(\mathrm{D}_{2} \mathrm{O}\right): \delta 61.03\left(\mathrm{C}-5^{\prime}\right), 69.73\left(\mathrm{C}-2^{\prime}\right), 74.15\left(\mathrm{C}-3^{\prime}\right), 84.50,89.66\left(\mathrm{C}-4^{\prime}, \mathrm{C}-1^{\prime}\right)$, 102.48 (C-5), 142.12 (C-6), $151.83(\mathrm{C}-2 \mathrm{C}=\mathrm{O}), 166.33(\mathrm{C}-4 \mathrm{C}=\mathrm{O})$ ) ${ }^{31} \mathrm{P}$ NMR (in $\mathrm{D}_{2} \mathrm{O}$ and $\mathrm{H}_{3} \mathrm{PO}_{4}$ $85 \%$ in water as external standard): $\delta 44.88$ (s); HR-MS (ESI-TOF) (m/z) calcd. 340.2469, found, $341.2403[\mathrm{M}+\mathrm{H}]^{+}$.

Adenosine-5'-O-monothiophosphate (18m). ${ }^{1} \mathrm{H}$ NMR (DMSO- $\left.d_{6}\right): \delta 3.94-4.02(\mathrm{~m}, \mathrm{H}-5$ ', $1 \mathrm{H})$, 4.02-4.10 (m, H-5", 1H), 4.07-4.15 (m, H-4', 1H), 4.16-4.22 (m, H-3', 1H), 4.60 (dd, $J_{2^{\prime}, 1^{\prime}}=5.7$, $\left.J_{2^{\prime}, 3^{\prime}}=5.3 \mathrm{~Hz}, \mathrm{H}-2^{\prime}, 1 \mathrm{H}\right), 5.95\left(\mathrm{~d}, J_{1^{\prime}, 2^{\prime}}=5.7 \mathrm{~Hz}, \mathrm{H}-1^{\prime}, 1 \mathrm{H}\right), 7.80-8.00\left(\mathrm{br} \mathrm{s}, 6-\mathrm{NH} H_{2}, 2 \mathrm{H}\right), 8.17(\mathrm{~s}$, H-2, 1H), 8.23 (s, H-8, $1 \mathrm{H}) ;{ }^{13} \mathrm{C}$ NMR (DMSO- $\left.d_{6}\right): \delta 65.96$ (C-5'); 71.31 (C-2'), 74.45 (C-3'), 84.19, 87.99 (C-4', C-1'), 119.67 (C-5), 140.72 (C-8), 150.14 (C-4), 151.90 (C-2), 155.58 (C-6); ${ }^{31} \mathrm{P}$ NMR (DMSO and $\mathrm{H}_{3} \mathrm{PO}_{4} 85 \%$ in water as external standard): $\delta 47.45$ (s); HR-MS (ESI-TOF) $(\mathrm{m} / \mathrm{z})$ calcd. 363.2868 , found $364.2829[\mathrm{M}+\mathrm{H}]^{+}$.

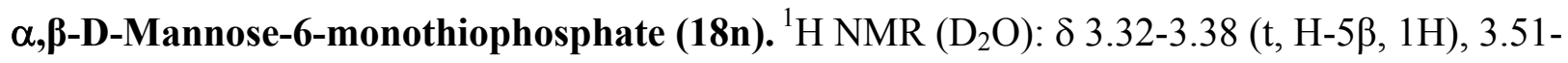

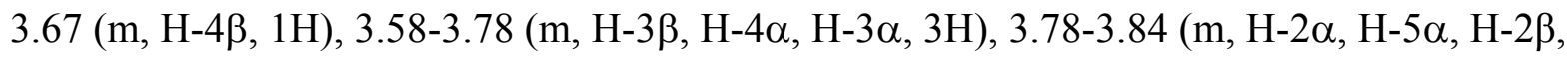
$3 \mathrm{H}) 3.84-3.93(\mathrm{~m}, \mathrm{H}-6 \alpha, \mathrm{H}-6 \beta, 4 \mathrm{H}), 4.87$ (d, H-1 $\left.\beta, J_{1,2}=1.2 \mathrm{~Hz}, 1 \mathrm{H}\right), 5.15\left(\mathrm{~d}, \mathrm{H}-1 \alpha, J_{1,2}=2.0\right.$ $\mathrm{Hz}, 1 \mathrm{H}$ ); ${ }^{31} \mathrm{P}$ NMR (in $\mathrm{D}_{2} \mathrm{O}$ and $\mathrm{H}_{3} \mathrm{PO}_{4} 85 \%$ in water as external standard): $\delta 54.78(\mathrm{~s}) ;{ }^{13} \mathrm{C}$ NMR 
$\left(\mathrm{D}_{2} \mathrm{O}\right): \delta 61.30(\mathrm{C}-6, \alpha$ and $\beta), 66.92(\mathrm{C}-4 \beta), 67.16(\mathrm{C}-4 \alpha), 70.54(\mathrm{C}-3 \alpha), 70.98(\mathrm{C}-2 \alpha), 71.52$

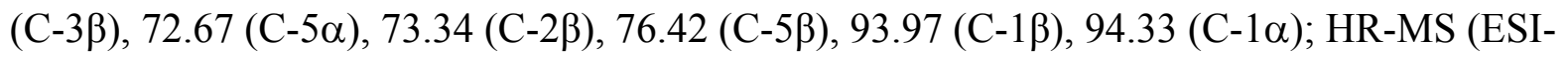
TOF) (m/z) calcd. 276.2014; found: $277.2050[\mathrm{M}+\mathrm{H}]^{+}$. Anal. Calcd. P 11.21\%, found $11.16 \%$.

6-O- $\alpha$-D-Galactopyranosyl-6'-O-thiophosphate- $\alpha, \beta$-D-glucose (180). ${ }^{1} \mathrm{H}$ NMR $\left(\mathrm{D}_{2} \mathrm{O}\right): \delta 3.13-$ 3.20 (m, H-2 $\beta, 1 \mathrm{H}$ ), 3.37-3.49 (m, H-4 $\alpha, \mathrm{H}-4 \beta, \mathrm{H}-3 \beta, 3 \mathrm{H}$ ), 3.52-3.70 (m, H-2 $\alpha, \mathrm{H}-2 \beta, \mathrm{H}-3 \alpha, \mathrm{H}-$

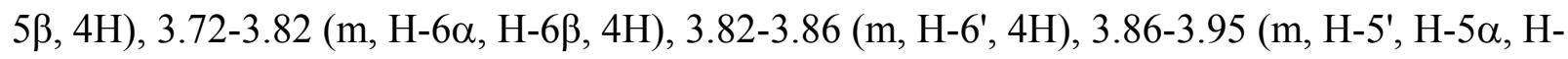
4', H-3', H-2', 9H), 4.56-4.65 (m, H-1', 2H), 5.12 (m, H-1ß, 1H); 5.18 (m, H-1 $\alpha, 1 \mathrm{H}) .{ }^{31}$ P NMR

(in $\mathrm{D}_{2} \mathrm{O}$ and $\mathrm{H}_{3} \mathrm{PO}_{4} 85 \%$ in water as external standard): $\delta 50.17$ (s). ${ }^{13} \mathrm{C}$ NMR $\left(\mathrm{D}_{2} \mathrm{O}\right): \delta 61.48(\mathrm{C}-$

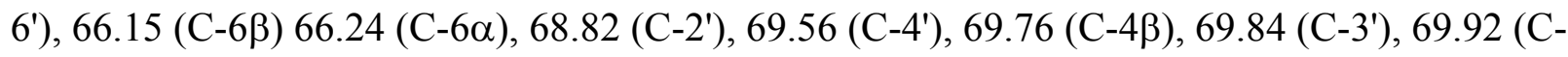

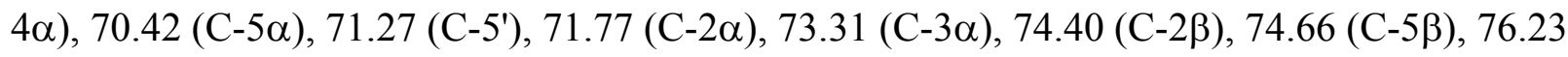

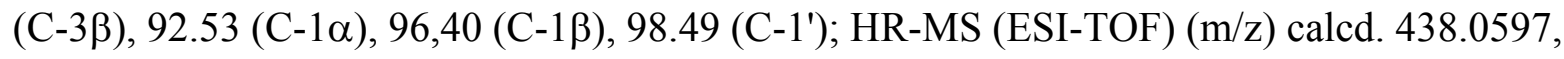
found $438.0102[\mathrm{M}]^{+}, 419.2013\left[\mathrm{M}-\mathrm{H}_{2} \mathrm{O}-\mathrm{H}\right]^{+}$. Anal. Calcd. P 7.07\%, found 7.10\%.

4. Solid-phase monophosphorylation using acetamidomethyl NovaGel ${ }^{\mathrm{TM}}$ resin bound-1,3,2oxathiaphospholane (6).

Preparation of NovaGel ${ }^{\mathrm{TM}}$ resin-bound 2,3-dimercapto-1-propanol (5).

Bromoacetamidomethyl NovaGel ${ }^{\mathrm{TM}}$ resin (4, 5.0 g, 100-200 mesh, DVB (1\%), $\left.0.64 \mathrm{mmol} / \mathrm{g}\right)$ was swelled in dry NMP $(35 \mathrm{~mL})$ and was shaken at room temperature for $15 \mathrm{~min} .2,3-$ Dimercapto-1-propanol (1,284 $\mu \mathrm{L}, 12.8 \mathrm{mmol})$ and potassium carbonate $(1.77 \mathrm{~g}, 12.8 \mathrm{mmol})$ were added to the swelled resin. The shaking was continued for $24 \mathrm{~h}$ at room temperature. The 
resin was filtered and washed with dry NMP $(2 \times 35 \mathrm{~mL})$, dry DCM $(2 \times 35 \mathrm{~mL})$, dry MeOH $(3$ $\times 35 \mathrm{~mL})$ and dried under vacuum to give $5(5.136 \mathrm{~g}, 98 \%, 0.61 \mathrm{mmol} / \mathrm{g})$. IR $\left(\mathrm{cm}^{-1}\right): 3499(\mathrm{OH})$.

\section{Preparation of NovaGel ${ }^{\mathrm{TM}}$ resin-bound 2-( $N, N$-diisopropylamine)-1,3,2-}

oxathiaphospholane (6). $N, N$-Diisopropyl phosphoramidite dichloride $(1,800 \mu \mathrm{L}, 12.8 \mathrm{mmol})$

and pyridine $(1,035 \mu \mathrm{L}, 12.8 \mathrm{mmol})$ were added to a swelled solution of $5(5.136 \mathrm{~g}, 0.61$

$\mathrm{mmol} / \mathrm{g})$ in anhydrous NMP $(35 \mathrm{~mL})$. The mixture was shaken for $24 \mathrm{~h}$ at room temperature. The resin was collected by filtration and washed with NMP $(2 \times 30 \mathrm{~mL})$, DCM $(2 \times 30 \mathrm{~mL})$, and dry $\mathrm{MeOH}(3 \times 30 \mathrm{~mL})$, respectively, and dried under vacuum to give $6(5.524 \mathrm{~g}, 96 \%, 0.55$

mmol/g). IR $\left(\mathrm{cm}^{-1}\right): 3515(\mathrm{OH}), 1029$ (P-O-C). Polymer-bound 2-(N,N-diisopropylamine)-1,3,2oxathiaphospholane (6) was stable at room temperature for $24 \mathrm{~h}$ drying period and was kept at $20^{\circ} \mathrm{C}$ for two weeks before using in the next reaction.

Preparation of NovaGel ${ }^{\mathrm{TM}}$ resin-bound 5'-O-(1,3,2-oxathiaphospholane)thymidine (8a), 5'$O$-(1,3,2-oxathiaphospholane)uridine $(8 \mathrm{~b}), 5^{\prime}-O-(1,3,2-0 x a t h i a p h o s p h o l a n e)$ adenosine (8c), 6-O-(1,3,2-oxathiaphospholane)- $\alpha, \beta-D-m a n n o s e ~(8 d)$, and 6'-O-(1,3,2-oxathiaphospholane)6- $\boldsymbol{O}$ - $\boldsymbol{\alpha}$-D-galactopyranosyl- $\boldsymbol{\alpha}, \boldsymbol{\beta}$-D-glucose (8e). Nucleosides or carbohydrates (a-e, $1.20 \mathrm{mmol}$ ) and $1-H$-tetrazole $(64 \mathrm{mg}, 0.90 \mathrm{mmol})$ were added to $6(500 \mathrm{mg}, 0.55 \mathrm{mmol} / \mathrm{g})$ in anhydrous THF (2-3 mL) and DMSO (3-5 mL). The mixture was shaken for $24 \mathrm{~h}$ at room temperature. The resin was collected by filtration and washed with DMSO $(3 \times 15 \mathrm{~mL})$, THF $(2 \times 10 \mathrm{~mL})$, and $\mathrm{MeOH}(3 \times 15 \mathrm{~mL})$, respectively, and dried under vacuum to give 8a-e $(519-577 \mathrm{mg})$. IR $\left(\mathrm{cm}^{-1}\right)$ : 
8a: 3434 (OH), 1030 (P-O-C); 8b:3418 (OH), 1029 (P-O-C); 8c: 3409 (OH), 1030 (P-O-C); 8d: $3422(\mathrm{OH}), 1029$ (P-O-C); 8e: $3416(\mathrm{OH}), 1022$ (P-O-C).

Oxidation of NovaGel ${ }^{\mathrm{TM}}$ resin-bound phosphitylated precursors, 8a-e, to polymer-bound 1,3,2-oxathiaphospholane phosphotrieseter derivatives of thymidine (10a), uridine (10b), adenosine(10c), $\alpha, \beta$-D-mannose (10d), and 6- $O$ - $\alpha$-D-galactopyranosyl- $\alpha, \beta$-D-glucose (10e). tert-Butyl hydroperoxide in decane (5-6 M) $(240 \mu \mathrm{L}, 1.20 \mathrm{mmol})$ was added to the resins (8a-e, 519-577 $\mathrm{mg}$ ) in THF ( $3 \mathrm{~mL})$. After $1 \mathrm{~h}$ shaking at room temperature, the resins were collected by filtration and washed with DMSO $(10 \mathrm{~mL})$, THF $(2 \times 10 \mathrm{~mL})$, and $\mathrm{MeOH}(3 \times 10 \mathrm{~mL})$, respectively, and were dried under vacuum to give 10a-e $(521-579 \mathrm{mg})$. IR $\left(\mathrm{cm}^{-1}\right)$ : 10a: $3401(\mathrm{O}-$ H), 1029 (P-O-C); 10b: 3388 (O-H), 1029 (P-O-C); 10c: 3375 (O-H), 1032 (P-O-C); 10d: 3376 (O-H), 1027 (P-O-C); 10e: 3356 (O-H), 1033 (P-O-C). Polymer-bound 1,3,2-oxathiaphospholane phosphotrieseter derivatives 10a-e were stable at room temperature for $24 \mathrm{~h}$ drying period and were used immediately after drying for the use in the next reaction.

Preparation of thymidine-5'-O-monophosphate (11f), uridine-5'-O-monophosphate (11g), adenosine-5'- $O$-monophosphate (11h), $\alpha, \beta$-D-mannose-6- $O$-phosphate (11i), and 6- $O$ - $\alpha$-Dgalactopyranosyl-6'- $\boldsymbol{O}$-phosphate- $\boldsymbol{\alpha}, \boldsymbol{\beta}$-D-glucose (11j). To the swelled resins (10a-e, $521-579$ $\mathrm{mg})$ in anhydrous DMSO (5 mL) was added DBU (120 $\mu \mathrm{L}, 1.20 \mathrm{mmol})$ and 3hydroxypropionitrile $(1.20 \mathrm{mmol}, 86 \mu \mathrm{L})$. After $48 \mathrm{~h}$ shaking of the mixture at room temperature, the resins were collected by filtration and washed with DCM $(2 \times 10 \mathrm{~mL})$, THF $(2$ $\times 10 \mathrm{~mL})$, and $\mathrm{MeOH}(3 \times 10 \mathrm{~mL})$, respectively. The solvents of filtrate solutions were immediately evaporated at room temperature for $11 \mathbf{f}$ and $11 \mathrm{~g}$ and at $-20{ }^{\circ} \mathrm{C}$ for $\mathbf{1 1 h}-\mathbf{j}$, 
respectively. The residues were mixed with Amberlite AG-50W-X8 (100-200 mesh, hydrogen form, $500 \mathrm{mg}, 1.7 \mathrm{meq} / \mathrm{g})$ in water:dioxane $(70: 30 \mathrm{v} / \mathrm{v}, 3 \mathrm{~mL})$ for $30 \mathrm{~min}$ at room temperature for 11 and $\mathbf{1 1 g}$ and at $-20^{\circ} \mathrm{C}$ for $\mathbf{1 1 h}-\mathbf{j}$, respectively. After filtration, the solvents were evaporated and the crude products were purified using $\mathrm{C}_{18}$ Sep-Pak using appropriate solvents. The solvents were evaporated and the residues were dried under vacuum to yield $\mathbf{1 1} \mathbf{f}-\mathbf{j}$. The total isolated yields for 11f-j were: $\mathbf{1 1 f}(68.5 \mathrm{mg}, 67 \%), \mathbf{1 1 g}$ (73.0 mg, 71\%), 11h (77 mg, 70\%), 11i (52.8, $64 \%), 11 \mathrm{j}(73.7,55 \%)$. The compounds were characterized by ${ }^{1} \mathrm{H}$ NMR, ${ }^{13} \mathrm{C}$ NMR, ${ }^{31} \mathrm{P}$ NMR and high resolution mass spectrometer (ESI-TOF). The chemical structures were confirmed with comparing their spectral properties with authentic samples purchased from Sigma-Aldrich and Acros Organics and literature. Compounds $\mathbf{1 1} \mathbf{i}^{38}$ and $\mathbf{1 1} \mathbf{j}^{30}$ have been previously characterized by ${ }^{1} \mathrm{H}$ NMR and ${ }^{13} \mathrm{C}$ NMR. Compounds $\mathbf{1 1 f},{ }^{39} \mathbf{1 1 g},{ }^{39}$ and $\mathbf{1 1} \mathbf{h}^{39-41}$ have been previously characterized by ${ }^{1} \mathrm{H}$ NMR. ${ }^{13} \mathrm{C}$ NMR of 11f, 11g, and 11h and ${ }^{31} \mathrm{P}$ NMR of 11f, 11g, 11h, 11i, and $\mathbf{1 1} \mathbf{j}$ were similar to those of compounds prepared from NovaSyn ${ }^{\mathrm{TM}}$ Tentagel resin as described above.

\section{Solid-phase monothiophosphorylation using NovaGel ${ }^{\mathrm{TM}}$ resin-bound $1,3,2-$ oxathiaphospholane (6).}

Sulfurization of NovaGel ${ }^{\mathrm{TM}}$ resin-bound phosphitylated precursors, 8a-e, to NovaSyn ${ }^{\mathrm{TM}}$ Tentagel resin-bound 1,3,2-oxathiaphospholane thiophosphotrieseter derivatives of thymidine (13a), uridine (13b), adenosine (13c), $\alpha, \beta$-D-mannose (13d), and 6- $O$ - $\alpha$-Dgalactopyranosyl- $\alpha, \boldsymbol{\beta}$-D-glucose (13e). Beuacage's reagent (3H-1,2-benzodithiole-3-one 1,1dioxide (234 mg, $1.17 \mathrm{mmol}$ ) was added to the resins (8a-e, 519-577 mg) in AcCN (4 mL). After 
$6 \mathrm{~h}$ shaking at $40^{\circ} \mathrm{C}$, the resins were collected by filtration and washed with $\mathrm{AcCN}(2 \times 10 \mathrm{~mL})$, THF $(2 \times 10 \mathrm{~mL})$, and $\mathrm{MeOH}(3 \times 10 \mathrm{~mL})$, respectively, and were dried under vacuum to give 13a-e (530-586 mg). IR ( $\left.\mathrm{cm}^{-1}\right)$ : 13a: $3410(\mathrm{O}-\mathrm{H}), 1029$ (P-O-C); 13b: 3406 (O-H), 1033 (P-OC); 13c: 3390 (O-H), 1029 (P-O-C); 13d: 3383 (O-H), 1029 (P-O-C); 13e: 3363 (O-H), 1034 (PO-C). Polymer-bound 1,3,2-oxathiaphospholane thiophosphotrieseter derivatives 13a-e were stable at room temperature for $24 \mathrm{~h}$ drying period and were used immediately after drying for the use in the next reaction.

Preparation of thymidine-5'-O-monothiophosphate (18k), uridine-5'-O-monothiophosphate (18I), adenosine-5'-O-monothiophosphate (18m), $\alpha, \beta$-D-mannose-6- $O$-thiophosphate (18n), and 6- $O$ - $\alpha$-D-galactopyranosyl-6'- $\boldsymbol{O}$-thiophosphate- $\alpha, \beta$-D-glucose (180). To the swelled resins (13a-e, $530-586 \mathrm{mg})$ in anhydrous DCM (5 mL) was added DBU (120 $\mu \mathrm{L}, 1.20 \mathrm{mmol})$ and 3-hydroxypropionitrile $(1.20 \mathrm{mmol}, 86 \mu \mathrm{L}))$. After $48 \mathrm{~h}$ shaking of the mixture at room temperature, the resins were collected by filtration and washed with DCM $(10 \mathrm{~mL})$, THF (10 $\mathrm{mL})$, and $\mathrm{MeOH}(10 \mathrm{~mL})$, respectively. The solvents of filtrate solutions were immediately evaporated at room temperature for $18 \mathrm{k}$ and $\mathbf{1 8 I}$ and at $-20{ }^{\circ} \mathrm{C}$ for $\mathbf{1 8 m - o}$, respectively. The residues were mixed with Amberlite AG-50W-X8 (100-200 mesh, hydrogen form, 500 mg, 1.7 meq/g) in water:dioxane $(70: 30 \mathrm{v} / \mathrm{v}, 3 \mathrm{~mL})$ for $30 \mathrm{~min}$ at room temperature for $\mathbf{1 8 k}$ and $\mathbf{1 8 I}$ and at $-20{ }^{\circ} \mathrm{C}$ for $\mathbf{1 8 m - \mathbf { o }}$, respectively. After filtration, the solvents were evaporated and the crude products were purified using $\mathrm{C}_{18}$ Sep-Pak using appropriate solvents. The solvents were evaporated and the residues were dried under vacuum to yield 18k-o. The total isolated yields for 18k-o were: 18k (69.8 mg, 65\%), $18 \mathbf{l}$ (75.5 mg, 70\%), 18m (84.1 mg, 73\%), 18n (49.2 mg, 56\%), 180 (73.7 mg, 53\%). The compounds were characterized by ${ }^{1} \mathrm{H} N M R,{ }^{13} \mathrm{C} N M R,{ }^{31} \mathrm{P}$ 
NMR, and high resolution mass spectrometer (ESI-TOF). The spectral properties of $\mathbf{1 8 k - 0}$ were similar to those of compounds prepared from NovaSyn ${ }^{\mathrm{TM}}$ Tentagel resin as described above. 


\section{References for physical and spectral properties:}

38. Meldal, M.; Christensen, M. K., Bock, K. Carbohydr. Res. 1992, 235, 115-127.

39. Schneider, H.-J.; Blatter, T.; Palm, B.; Pfingstag, U.; Rüdiger, V.; Theis, I. J. Am. Chem. Soc. 1992, 114, 7704-7708.

40. Shi, Y.; Schneider, H.-J. J. Chem. Soc., Perkin Trans. 1999, 2, 1797-1803.

41. Eliseev, A. V., Schneider, H.-J. J. Am. Chem. Soc. 1994, 116, 6081-6088. 